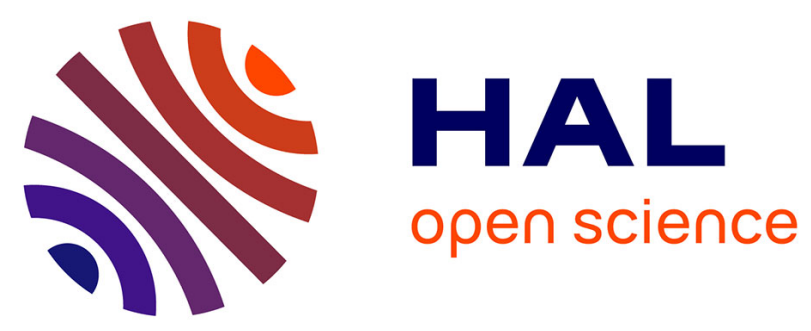

\title{
0D modeling aspects of flame stretch in spark ignition engines and comparison with experimental results
}

Sokratis Demesoukas, Pierre Brequigny, Christian Caillol, Fabien Halter,

Christine Mounaïm-Rousselle

\section{- To cite this version:}

Sokratis Demesoukas, Pierre Brequigny, Christian Caillol, Fabien Halter, Christine MounaïmRousselle. 0D modeling aspects of flame stretch in spark ignition engines and comparison with experimental results. Applied Energy, 2016, 179, pp.401 - 412. 10.1016/j.apenergy.2016.07.007 . hal-01934602

\section{HAL Id: hal-01934602 \\ https://hal.science/hal-01934602}

Submitted on 20 Mar 2019

HAL is a multi-disciplinary open access archive for the deposit and dissemination of scientific research documents, whether they are published or not. The documents may come from teaching and research institutions in France or abroad, or from public or private research centers.
L'archive ouverte pluridisciplinaire HAL, est destinée au dépôt et à la diffusion de documents scientifiques de niveau recherche, publiés ou non, émanant des établissements d'enseignement et de recherche français ou étrangers, des laboratoires publics ou privés. 


\title{
0D modeling aspects of flame stretch in spark ignition engines and comparison with
}

\section{experimental results}

\author{
Sokratis Demesoukas ${ }^{\mathrm{a}}$, Pierre Brequignya ${ }^{*}$, Christian Caillol $^{\mathrm{a}}$, Fabien Halter ${ }^{\mathrm{a}}$, Christine Mounaïm-Rousselle $^{\mathrm{a}}$ \\ ${ }^{a}$ Laboratoire PRISME, Université d'Orléans, 8 rue Léonard de Vinci, 45072 Orléans Cedex 2, France
}

\begin{abstract}
With the different kinds of fuel now available, modern spark ignition engines have to be adapted, owing not only to the difference between the characteristic heat of combustion of the different fuels, but also to the response of the flame to stretch. As the burning rate is a function of the laminar burning speed which is a function of the flame stretch, this parameter has to be taken into account by combustion models.
\end{abstract}

In this study, a zero-dimensional combustion model, based on the Flame Surface Density equation, is enhanced with a model for the stretched laminar burning speed. Numerical results are compared with the experimental results of three lean air-fuel mixtures with isooctane, propane and methane as fuels, that have similar unstretched laminar burning speeds but different Lewis numbers. Laminar burning speed, flame radius, burnt mass fraction, and turbulent flame wrinkling are compared with experimental results. The simulation trends are similar to those of experimental results. Methane and propane (Lewis number 0.99 and 1.80 respectively) show similar wrinkling rates, while isooctane (Lewis number 2.90) has a lower wrinkling rate. The observed difference between computed burnt mass fraction with stretched and unstretched flame speed models reveals

\footnotetext{
* Corresponding author

E-mail address: pierre.brequigny@univ-orleans.fr
} 
that the impact of stretch and Lewis number needs to be taken into account and that a stretched laminar burning speed must be used for modeling, especially for mixtures with a Lewis number much greater than unity.

\section{Keywords}

Spark ignition engine, 0D combustion modeling, flame stretch, Lewis number, fuel effect

\section{Nomenclature}

\begin{tabular}{|c|c|c|c|}
\hline Latin & & Greek & \\
\hline$A$ & surface $\left(\mathrm{m}^{2}\right)$ & $\Gamma$ & efficiency function (-) \\
\hline$B$ & pressure constant $\left(10^{5} \mathrm{~Pa}\right)$ & $\delta_{L}$ & Blint's laminar flame thickness(m) \\
\hline$D$ & Destruction term $\left(\mathrm{m}^{2} / \mathrm{s}\right)$ & $\delta_{L}^{0}$ & laminar flame thickness (m) \\
\hline$D_{m}$ & Mass (Species) diffusivity $\left(\mathrm{m}^{2} / \mathrm{s}\right)$ & $\kappa$ & flame curvature $\left(\mathrm{m}^{-1}\right)$ \\
\hline$D_{t h}$ & Thermal diffusivity $\left(\mathrm{m}^{2} / \mathrm{s}\right)$ & $\Xi$ & wrinkling factor (-) \\
\hline$D a$ & Damköhler number & $\rho$ & density $\left(\mathrm{kg} / \mathrm{m}^{3}\right)$ \\
\hline$E$ & temperature constant $(\mathrm{K})$ & $\sigma$ & fresh to burnt density ratio (-) \\
\hline$H$ & specific enthalpy $(\mathrm{J} / \mathrm{kg})$ & Subscripts & \\
\hline$K$ & Mean kinetic energy $(\mathrm{J})$ & 0 & standard or unstretched \\
\hline$k$ & Turbulent kinetic energy $(\mathrm{J})$ & $b$ & burnt gases \\
\hline$K a$ & Karlovitz number (-) & $\mathrm{c}$ & consumption speed \\
\hline Le & Lewis number (-) & $c o m b$ & combustion \\
\hline$M$ & molar mass $(\mathrm{g} / \mathrm{mol})$ & $e q u$ & equilibrium \\
\hline$m$ & $\operatorname{mass}(\mathrm{kg})$ & $L$ & laminar flame \\
\hline$M a$ & Markstein number (-) & $R$ & propagation speed \\
\hline$P$ & Production term $(\mathrm{J} / \mathrm{s})$ & $u$ & fresh (unburnt) gases \\
\hline$p$ & pressure $(\mathrm{Pa})$ & Acronyms & \\
\hline$R_{f}$ & flame radius $(\mathrm{m})$ & CAD & Crank Angle Degrees \\
\hline$S$ & laminar burning speed $(\mathrm{m} / \mathrm{s})$ & CFD & Computational Fluid Dynamics \\
\hline$T$ & temperature $(\mathrm{K})$ & EGR & Exhaust Gas Recirculation \\
\hline$u^{\prime}$ & turbulent intensity $(\mathrm{m} / \mathrm{s})$ & IVC & Inlet Valve Closing \\
\hline$V$ & volume $\left(\mathrm{m}^{3}\right)$ & RBG & Residual Burnt Gas \\
\hline$X$ & mole fraction (-) & TDC & Top Dead Center \\
\hline$Y$ & mass fraction (-) & SI & Spark Ignition \\
\hline$Z e$ & Zeldovich number (-) & & \\
\hline
\end{tabular}




\section{Introduction}

Nowadays, due to the increasingly restrictive standards on pollutants and $\mathrm{CO}_{2}$ emissions, the car industry is developing new technologies which require fuel adaptation. Moreover, in order to compensate for the depletion of fossil energy resources, oil companies have introduced biofuels for Spark-Ignition (SI) engines. These fuels can be used either pure or blended with gasoline. As a result, the automotive and oil industries are facing a context of fuel diversification.

However, the use of various fuels in a SI engine can be responsible for a different combustion behavior and could therefore impact the pollutant emissions [1], auto-ignition delays [2] but also the engine efficiency. For SI engines, the heat release rate is linked to the flame propagation speed of the expanding flame kernel. In addition, while aiming at improving efficiency, oil companies have sought to develop fuels that burn faster than typical gasoline. However, in a SI engine, the kernel expansion flame speed depends not only on the fuel but also on several additional phenomena such as turbulence [3], flame stretch [4] and type of ignition system [5]. As a first step to evaluate potential substitutes for gasoline, the fundamental laminar burning speed is mainly investigated [6-10]. Moreover, it is a key parameter for combustion modeling [11]. This burning speed corresponds to the speed of a one-dimensional planar adiabatic flame in laminar conditions without any instability and it is a function of pressure, temperature, fuel, dilution and fuel/air equivalence ratio. The fundamental laminar burning speed cannot be considered as the consumption speed of an expanding flame, however, since the flame speed of expanding flames is submitted to stretch, which contains two contributions: curvature and strain rate [12]. Flame stretch, which can be defined as the relative growth rate of the flame surface, is related to the thermo-diffusive characteristics of the fuel [13-15].

Therefore, depending on the fuel used, the different responses to flame stretch will impact the flame propagation differently. While this effect has been fully investigated in laminar conditions 
[16-18], only a few recent studies have presented the effect of flame stretch in SI engines [19-22].

Besides, only a few Computational Fluid Dynamics (CFD) models for spark ignition consider the laminar burning speed dependence on the flame stretch [23-25] and many models are mainly based on the unstretched laminar burning speed. It is still an open question, however, how to take flame stretch phenomena into account.

In a previous study [19], the impact of the engine speed and of the air/fuel mixture (air with isooctane, propane and methane at different fuel/air equivalence ratios) on the flame stretch rate was studied. It was shown that the flame stretch sensitivities observed in the laminar regime directly impact the combustion process inside the engine. In order to validate the results, an accurate study of flame visualization was performed and the results can be found in [21]. Different lean mixtures presenting almost the same unstretched laminar burning speed were selected. The mixtures also had different Lewis numbers which is a relevant parameter to describe thermodiffusive instabilities as well as flame stretch interactions. Global flame wrinkling and local flame curvature were also studied.

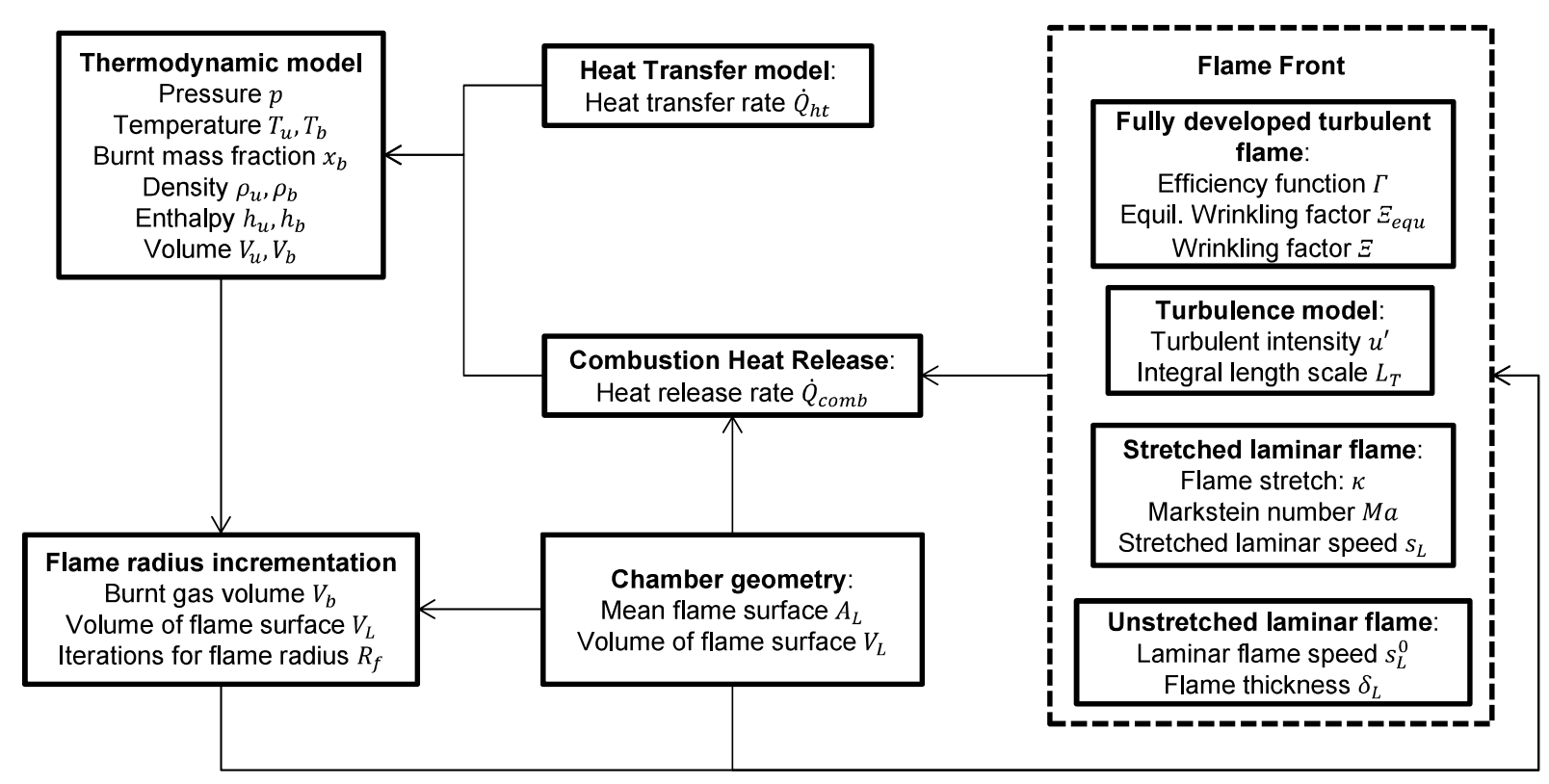

Calculation loop for crank angle step

Figure 1: Schematic representation of the combustion model 
Recently OD models have shown great interest for reproducing engine performances with a computational cost that is competitive compared to CFD codes. Even though 0D modeling is less detailed in the description of the physics than the LES technique, it is able to reproduce complex phenomena such as pollutant emissions for SI engines [26], blow-by leakage, fuel injection and engine deformations for direct injection Diesel engines [27]. A OD model was developed [28] by the authors on the basis of the zero dimensional (0D) Flame Surface Density equation [29] and in the present work, it is enhanced with a sub-model for laminar flame stretch. The mean flame surface is considered to be a sphere, which intersects with the chamber wall. The model calculates a flame radius as well as a flame wrinkling factor and is coupled with a two-zone thermodynamic model. A schematic representation of the model is shown in Figure 1. This paper focuses on reproducing the previously reported experimental results [21] through 0D modeling, to clarify at which combustion stage flame stretch is important to consider and why the stretched laminar burning speed must be taken into account in SI combustion models.

The main objectives of this paper are:

- To propose a new 0D model that takes into account the effect of stretch on flame propagation for a Spark-Ignition engine

- To better understand the role of wrinkling and stretch in the flame speed evolution.

- To address new comparisons with experimental results obtained from an optical engine to validate the model. In particular, the calculated burnt mass fraction and in-cylinder pressure, which are key parameters when calibrating a new engine, are compared to experimental data.

This study finally demonstrates the importance of taking stretch into account, especially curvature in the laminar flame speed formulation, to better predict the burnt mass fraction. With such a 
modification, the overall model is not only able to satisfactorily predict the end of the combustion phase as developed in previous studies [30,31] but it is also relevant for the early flame propagation phases when flame stretch is high. It is thus a powerful tool for predicting the performances of a new SI engine design with different kinds of fuel and in a wide range of conditions.

\section{Model}

In this section the combustion model is briefly presented. Some sub-models were described in a previous study [28] and are briefly covered here. In order to simulate the compression and combustion stages in a SI engine, a two-zone thermodynamic model was used. This kind of modeling takes into account two zones, one for the unburnt (fresh) gases and one for the burnt gases. The equations of this model are the results of the energy conservation inside the combustion chamber. For the heat transfer $(Q)$ modeling, a classical Woschni [32] approach was used. This model is connected with the combustion model and it calculates cylinder pressure $(p)$, fresh and burnt gas temperatures and densities $\left(T_{u}, T_{b}, \rho_{u}, \rho_{b}\right)$ as well as fresh and burnt gas compositions. The detailed derivation of the thermodynamic model can be found in [33].

The heat release rate of combustion $\left(Q_{c o m b}\right)$ can be estimated from the simulated cylinder pressure $(p)$ as a function of the crank angle $(\theta)(\gamma$ is the ratio of heat capacities under constant pressure and constant volume and $V$ is the cylinder volume):

$$
\frac{d Q_{c o m b}}{d \theta}=\frac{\gamma}{\gamma-1} p \frac{d V}{d \theta}+\frac{1}{\gamma-1} V \frac{d p}{d \theta}+\frac{d Q}{d \theta}
$$

Under the flamelet assumption, the combustion reaction is assumed to be fast enough for the dominant effect of turbulence on the flame to be to wrinkle the flame surface, while the inner flame structure is not significantly altered by the turbulent flow field. The rate of burnt mass $\left(\dot{m}_{b}\right)$ is written:

$$
\dot{m}_{b}=\rho_{u} s_{L} A_{L} \Xi
$$


It contains the fresh gas density $\left(\rho_{u}\right)$, the laminar burning speed $\left(s_{L}\right)$, the mean flame surface $\left(A_{L}\right)$ and the wrinkling factor $(\Xi)$. The flame starts as a kernel of burnt gases in the vicinity of the spark plug and propagates towards the walls, while being wrinkled by turbulence. A basic assumption of 0D SI combustion modeling is that the flame starts as a sphere between the electrodes of the spark plug. While the flame propagates inside the cylinder, its mean surface $\left(A_{L}\right)$ as well as its volume $\left(V_{L}\right)$ remain spherical. A numerical tool of a simplified but realistic chamber geometry was developed. It takes into account the chamber geometry through its bore, stroke, and spark plug position and it represents properly enough the complex geometry of the cylinder head. It gives as an output the mean surface and the volume as a function of the piston height and of the flame radius $\left(R_{f}\right)$. Details about the model can be found in the work by Demesoukas [34]. The starting point of the flame radius is fixed between the spark plug electrodes. For each crank angle step, flame radius is calculated using an iterative process, so that the geometrical volume $\left(V_{L}\right)$ of burnt gases is equal to the burnt gas volume $\left(V_{b}\right)$ computed from the thermodynamic model. This calculation ensures consistency of the flame propagation. The temporal evolution of the flame radius is used to calculate a flame propagation speed $\left(s_{R}\right)$ :

$$
s_{R}=\frac{d R_{f}}{d t}
$$

\subsection{Laminar burning speed and flame thickness}

Laminar burning speed is one of the fundamental characteristics for modeling flame propagation. It is known that various correlations exist in the literature to calculate the laminar burning speed of typical fuels. The correlation can then be used in CFD simulation or 0D modeling, as done by Fanelli et al. with $\mathrm{H} 2 / \mathrm{CO}$ mixtures [35] . The choice of correlation (see

Table 1 for references) for each fuel was based on its validity under high pressure and temperature conditions, as is the case in SI engines. Empirical correlations of the form of eq. (4) which take 
into account the dependence of the fuel-air equivalence ratio $(\varphi)$, cylinder pressure $(p)$ and fresh gas temperature $\left(T_{u}\right)$ were used in the present study to determine the unstretched laminar burning speed $s_{L}^{0}$. In this work, experiments and simulations were carried out with no RBG, so this dependence was omitted in the unstretched laminar burning speed correlations. During the experiments the engine was fired every 6 cycles in order to avoid the presence of RBG. However, modern SI engine design strategies include the recirculation of burnt gas [36,37] and its impact on laminar burning speed has to be taken into account in the correlations to simulate the standard operation of a SI engine. The values of pressure and temperature exponents $(\alpha, \beta)$ as well as the mixture laminar flame speed $\left(s_{L}^{00}\right)$ are given in

Table 1. Reference pressure and temperature conditions $\left(p_{\text {ref }}, T_{u, r e f}\right)$ are also provided.

$$
s_{L}^{0}=s_{L}^{00}(\varphi)\left(\frac{p}{p_{\text {ref }}}\right)^{\alpha}\left(\frac{T_{u}}{T_{\text {u,ref }}}\right)^{\beta}
$$

Table 1: Constants for laminar flame correlation of isooctane, propane and methane

\begin{tabular}{|c|c|c|c|}
\hline & Isooctane [38] & Propane [39] & Methane [40] \\
\hline$\varphi(-)$ & 0.80 & 0.72 & 0.85 \\
\hline$s_{L}^{00}(\varphi)(\mathrm{m} / \mathrm{s})$ & 0.45 & 0.22 & 0.32 \\
\hline$p_{\text {ref }}\left(10^{5} \mathrm{~Pa}\right)$ & 1.0 & 1.0 & 1.0 \\
\hline$T_{u, \text { ref }}(\mathrm{K})$ & 423 & 300 & 300 \\
\hline$\alpha(-)$ & 1.93 & 1.63 & 1.81 \\
\hline$\beta(-)$ & -0.3129 & -0.18 & -0.44 \\
\hline
\end{tabular}

The laminar flame thickness $\left(\delta_{L}^{0}\right)$ can be defined as the ratio between the thermal diffusivity $\left(D_{t h}\right)$ and the unstretched laminar burning speed $\left(s_{L}^{0}\right)$. It is also called 'diffusive thickness'.

$$
\delta_{L}^{0}=\frac{D_{t h}}{S_{L}^{0}}
$$

As explained in [41], in practice the diffusive thickness is smaller than the actual values of laminar flame thickness. An alternative correlation, proposed by Blint in [42], takes into account the ratio 
of the burnt gas and fresh gas temperature. This correlation is used in the present study.

$$
\delta_{L}=2 \delta_{L}^{0}\left(\frac{T_{b}}{T_{u}}\right)^{0.7}
$$

The fresh gas mixture diffusion coefficient for species $k, D_{k m}$ was computed as described in [43]. The binary diffusion coefficients $D_{j k}$ for the fresh gas species (fuel, $\mathrm{CO}_{2}, \mathrm{H}_{2} \mathrm{O}, \mathrm{O}_{2}, \mathrm{~N}_{2}, \mathrm{H}_{2}$ and $\mathrm{CO}$ with $j, k=1 \ldots 7)$ were calculated at a temperature equal to the fresh gas temperature $\left(T_{u}\right)$, with the use of coefficients obtained after running the CHEMKIN Transport Package [44] for the fresh gas species. $\bar{M}$ is the mean molar weight of the fresh gases. $Y$ and $X$ represent mass and mole fractions of species respectively.

$$
D_{k m}=\frac{\sum_{j \neq k}^{7} X_{j} M_{j}}{\bar{M} \sum_{j \neq k}^{7} X_{j} / D_{j k}}
$$

The Lewis number $(L e)$ is defined as the ratio of thermal diffusivity of the mixture to the deficient species mass diffusivity, which is the fuel in lean mixture conditions so that $k=$ fuel in equation (7), thus giving:

$$
L e=\frac{D_{t h}}{D_{\text {fuel }_{m}}}
$$

\subsection{Turbulence}

As is well known, turbulence wrinkles the flame and increases its surface by changing its stretch and strain characteristics. Calculation of the wrinkling factor $(\Xi)$ needs an estimation of turbulence intensity $\left(u^{\prime}\right)$ and, in most models, of the integral length scale $\left(L_{T}\right)$. In this work a 0D turbulence model was used. It contains one equation for the global kinetic energy $(K)$ and one for the turbulent kinetic energy $(k)$ as described by the work of Bozza et al. [45]. The following equations describe the rate of change of the kinetic energy of the mean flow field and of the kinetic energy of the turbulent field. The mean kinetic energy, which enters the chamber, is transformed into turbulent 
kinetic energy (production term $P$ ) and also changes due to the mass flow into the exhaust and due to the density variation. The turbulent kinetic energy is produced by the transfer of the kinetic energy of the mean flow field, is destroyed by viscous dissipation and changes due to the variation in the density and in the flow at the exhaust valve. The production and the dissipation terms are modeled with the aid of characteristic times $\left(t_{P}, t_{D}\right)$ and coefficients $\left(c_{P}, c_{D}\right)$. Mean flow velocity $\left(U_{f}\right)$ and integral length scale $\left(L_{T}\right)$ are used to calculate the production term.

$$
\begin{gathered}
\frac{d K}{d t}=c_{\text {in }} \frac{1}{2} \dot{m}_{\text {in }} u_{\text {in }}^{2}+c_{\text {out }} \frac{1}{2} \dot{m}_{\text {out }} u_{\text {out }}^{2}-P+K \frac{\dot{m}_{\text {ex }}}{m}+K \frac{\dot{\rho}}{\rho} \\
\frac{d k}{d t}=P-D+k \frac{\dot{m}_{\text {ex }}}{m}+k \frac{\dot{\rho}}{\rho} \\
P=c_{P} \frac{K}{t_{P}} ; D=c_{D} \frac{k}{t_{D}} ; t_{P}=\frac{U_{f}}{L_{T}} ; t_{D}=\frac{u^{\prime}}{L_{T}}
\end{gathered}
$$

The crucial assumption is that turbulence is homogenous and isotropic throughout the combustion chamber. An experimental assessment [46] of the turbulent intensity of the engine used in this work was performed. The results were used to calibrate the $0 \mathrm{D}$ turbulent model. A thorough explanation of this model can be found in $[47,48]$.

\subsection{Flame Wrinkling}

In this work, the Flame Surface Density Model (FSD) was used. In the FSD model, the wrinkling factor is calculated by a 0D differential equation [49]:

$$
\underbrace{\frac{1}{\Xi} \frac{d \Xi}{d t}}_{\text {Wrinkling }}=\underbrace{\Gamma\left(\frac{u^{\prime}}{s_{L}^{0}}, \frac{L_{T}}{\delta_{L}}\right) \frac{u^{\prime}}{L_{T}}\left(\frac{\Xi_{\text {equ }}-\Xi}{\Xi_{\text {equ }}-1}\right)}_{\text {Turbulent Stretch }}-\underbrace{\frac{2}{R_{f}} \frac{\rho_{u}}{\rho_{b}}(\Xi-1) s_{L}^{0}}_{\text {Mean Stretch }}
$$

This equation is obtained by the reduction of a 3D CFD equation of the flame surface density as described in detail in [25]. The first RHS term represents the wrinkling of the flame by all turbulent scales, while the second term represents the mean stretch due to the thermal expansion of the spherical flame which diminishes the turbulent wrinkling of the flame front [25]. This formulation 
makes it possible to compare the total stretch term of equation (10) with stretch calculated by experimental flame visualizations, as described in [14]. The turbulent term contains the efficiency function of the turbulent flow $(\Gamma)$ and the equilibrium wrinkling factor $\left(\Xi_{\text {equ }}\right)$.

$$
\Xi_{e q u}=1+2 \frac{u^{\prime}}{s_{L}^{0}} \sqrt{\frac{C \cdot \Gamma}{S c}}
$$

The presence of the efficiency function in this model takes into account the laminar flame speed $\left(s_{L}\right)$ and the laminar flame thickness $\left(\delta_{L}\right)$ as well as the impact of all turbulent scales. The strain rate of the flame front, caused by a pair of counter-rotating vortices, is integrated for all turbulent scales, assuming that each scale wrinkles the flame front independently. A fitting is performed in order to find the final expression of $\Gamma$. The expression used in the present study can be found in $[41,50]$.

$$
\begin{gathered}
\log _{10}(\Gamma)=-\frac{1}{s+0.4} \exp (-s-0.4)+[1-\exp (-s+0.4)]\left[\sigma_{1}\left(\frac{u^{\prime}}{s_{L}^{0}}\right) s-0.11\right] \\
s=\log _{10}\left(\frac{L_{T}}{\delta_{L}}\right) ; \sigma_{1}=\frac{2}{3}\left\{1-\frac{1}{2} \exp \left[-\left(\frac{u^{\prime}}{s_{L}^{0}}\right)^{\frac{1}{3}}\right]\right\}
\end{gathered}
$$

The equilibrium wrinkling factor $\left(\Xi_{e q u}\right)$ is the result of the analytical solution of the steady onedimensional flame density equation [51]. It contains the calibrating coefficient $(C)$ of the combustion model and it is fuel dependent through the Schmidt number $(S c)$. The calibrating coefficient is changed to ensure that the simulated cylinder pressure matches the experimental one. A more detailed discussion about the implementation of this combustion model and the reasons for its selection in this work can be found in [28]. This model was also enhanced for near wall combustion phenomena [30,31]. However, this modeling was omitted in the present study, since those phenomena are weak during the first combustion stage. 


\subsection{Stretched laminar burning speed}

The stretched laminar burning speed can be calculated as a function of the Markstein $(M a)$ number, of the flame curvature $(\kappa)$ and of the dimensional laminar flame thickness $\left(\delta_{L}^{0}\right)$, as proposed in [24].

$$
\begin{gathered}
\kappa=\frac{2}{R_{f}} \\
s_{L}=s_{L}^{0}\left(1-M a \cdot \delta_{L}^{0} \cdot \kappa\right)
\end{gathered}
$$

The strain rate is reported to make a minor contribution to the modification of burning speed in comparison with the mean curvature [24] during the early propagation stages. According to Bechtold and Matalon [52], the Markstein number $(\mathrm{Ma})$ can be calculated as follows $\left(\sigma=\rho_{u} / \rho_{b}\right)$ :

$$
\begin{gathered}
M a=\alpha-(\sigma-1) \frac{\gamma_{1}}{\sigma} \\
\alpha=\gamma_{1}+0.5 Z e(L e-1) \gamma_{2} \\
\gamma_{1}=\frac{2 \sigma}{\sqrt{\sigma}+1} \\
\gamma_{2}=\frac{4}{\sigma-1}\{\sqrt{\sigma}-1-\ln [0.5(\sqrt{\sigma}+1)]\}
\end{gathered}
$$

The Zeldovich number Ze is calculated following [53], with $T_{0}$ defined in [54]

$$
\begin{gathered}
Z e=4 \frac{T_{b}-T_{u}}{T_{b}-T_{0}} \\
T_{0}=-\frac{E}{\ln \frac{p}{B}}
\end{gathered}
$$


The constants ( $E$ and $B)$ were taken from [53] and their values are shown in

Table 2.

Table 2: Constants [53] for the calculation of $T_{0}$ temperature for all three fuels

\begin{tabular}{|c|c|c|c|}
\hline & Isooctane & Propane & Methane \\
\hline$E(\mathrm{~K})$ & 20906 & 17223.5 & 23873 \\
\hline$B\left(10^{5} \mathrm{~Pa}\right)$ & $3.8 \cdot 10^{7}$ & $2.2501 \cdot 10^{6}$ & $3.1557 \cdot 10^{8}$ \\
\hline
\end{tabular}

\section{Experimental setup}

Table 3. Test Engine characteristics

\begin{tabular}{|l|c|}
\hline Displaced volume $\left(\mathrm{cm}^{3}\right)$ & 500 \\
\hline Bore $(\mathrm{mm})$ & 88 \\
\hline Stroke $(\mathrm{mm})$ & 82 \\
\hline Connecting rod length (mm) & 137 \\
\hline Geometric compression ratio & 9.5 \\
\hline Number of valves & 4 \\
\hline Engine speed (rpm) & 1200,1600 \\
\hline $\begin{array}{l}\text { Spark advance (crank angle } \\
\text { degrees before Top Dead Center) }\end{array}$ & 30 \\
\hline Intake pressure (bar) & 0.7 \\
\hline Intake temperature $\left({ }^{\circ} \mathrm{C}\right)$ & 100 \\
\hline
\end{tabular}

The results obtained from the $0 \mathrm{D}$ model were compared to the experimental results obtained in [21]. The experimental set-up has been fully described in several references $[19,21,46,55]$. The optical engine specifications are summarized in Table 3. In [21], experimental results were deduced from images obtained with Mie-Scattering Tomography. As previously said, no residual burnt gases were present in the cylinder during the experiment since the engine was fired only once every 6 cycles. The experimental results obtained from images are averaged results of 50 consecutive firing cycles. The uncertainty on the averaged flame radius was estimated to be around $\pm 7 \%[22]$. 


\section{Results and discussion}

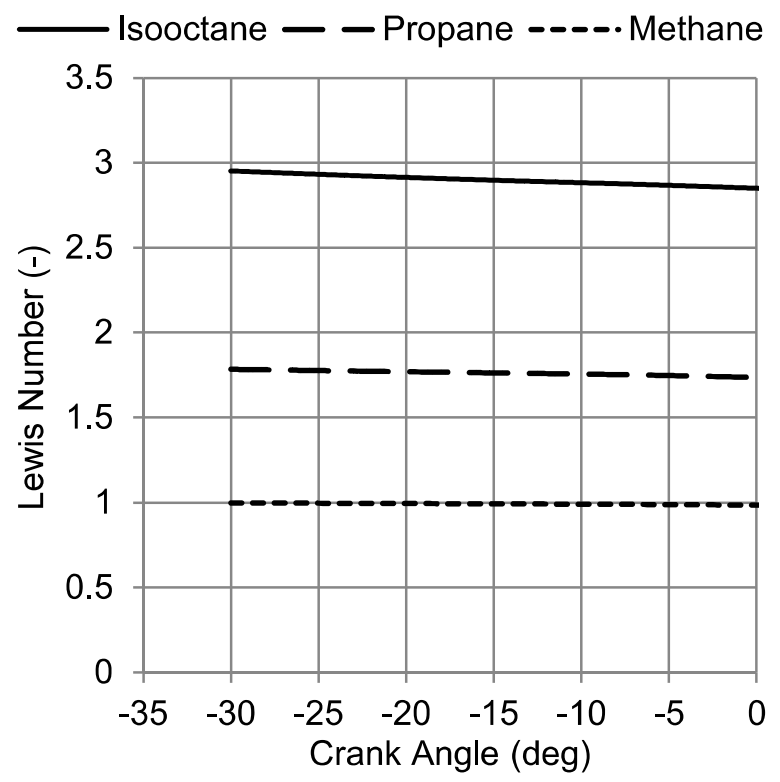

Figure 2: Lewis number during the combustion phase for all three fuels.

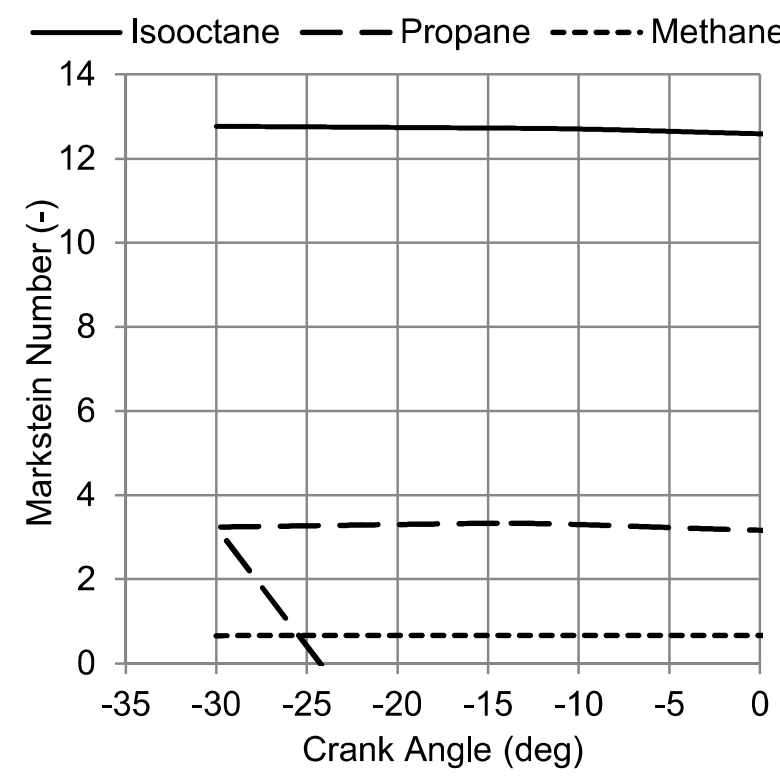

Figure 3: Markstein number during the combustion phase for all three fuels.

A basic validation of the simulations consists in calculating the characteristic non-dimensional combustion numbers, checking whether they agree with already published results and exploring their evolution during the engine cycle, during which pressure and temperature evolve. In Figure 2, the Lewis numbers (calculated with equation (8)) for all three fuels are plotted during the combustion cycle. They remain almost constant during combustion and their values match with the ones calculated by CHEMKIN at $6.1 \cdot 10^{5} \mathrm{~Pa}$ and $565.5 \mathrm{~K}$ (mean values of the measured engine cycle: $0.99,1.82$ and 2.85 for methane, propane and isooctane respectively) [21]. The Markstein number results for all three fuels are shown in Figure 3. Following the trend for the Lewis number, the Markstein number remains quasi-constant during the combustion process. The Markstein numbers for all three fuels are in agreement with the derived values in $[21](0.65,3.25$ and 12.80 for methane, propane and isooctane respectively). The consistency of the calculated Markstein and Lewis numbers as well as the fact that they remain quasi constant during the cycle means that the 
thermodiffusive and stretch characteristics can be connected with the stretched laminar burning speed.
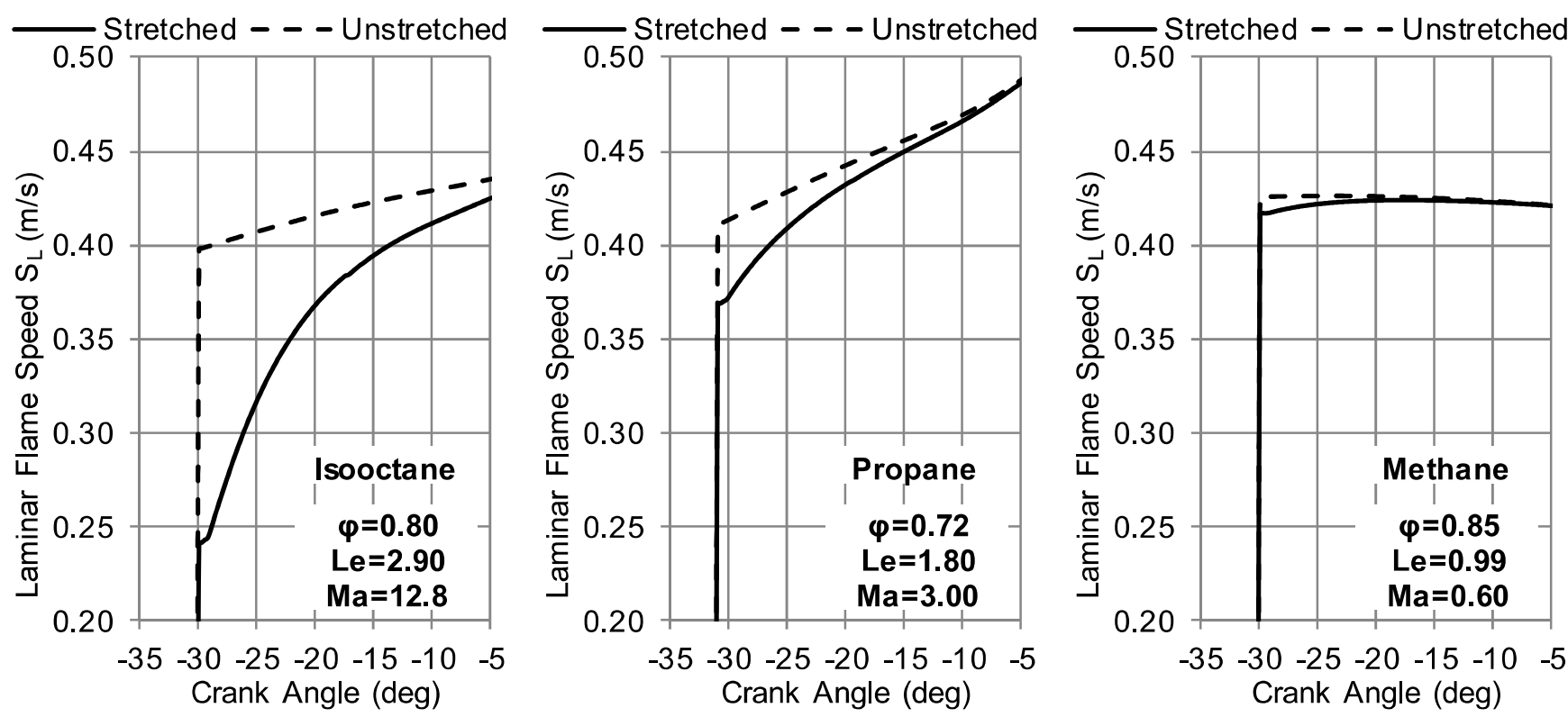

Figure 4: Stretched $\left(s_{L}\right)$ and unstretched $\left(s_{L}^{0}\right)$ laminar burning speeds after spark ignition for the experimental pressure and temperature conditions: (a) Isooctane, (b) Propane, (c) Methane.

The results of the model for the laminar burning speeds of the three fuels (equation (14)) are presented in Figure 4. The unstretched laminar burning speeds were calculated with the correlations adopted in section 2.1 (dashed line). The unstretched laminar burning speed is almost identical for all three fuels. It varies from 0.40 to $0.50 \mathrm{~m} / \mathrm{s}$ for the Crank Angle Degrees (CAD) between -30 and 0 .

The stretched laminar burning speed for the three fuels is smaller than the unstretched laminar burning speed. This observation was expected since the Markstein numbers for all fuels are positive. At spark ignition, the stretched laminar burning speed is diminished by $40 \%$ for isooctane, $13 \%$ for propane and $1 \%$ for methane. Therefore, isooctane is much more sensitive to flame stretching than propane and methane.

Another important observation is that for all fuels the impact of flame stretch is dominant at the beginning of combustion. The fact that the flame stretch is preponderant during the beginning of 
a premixed expanding spherical flame is expected, since it is inversely proportional to the flame radius, as shown in [41] for laminar premixed spherically expanding flames. As a consequence of the laminar and highly stretched flame, the modeling of the stretched laminar burning speed is important to predict the beginning of combustion more accurately.

Tracing the combustion regime of the turbulent flame of each fuel mixture will provide valuable insight into flame wrinkling and stretch. Turbulence characteristics (turbulent intensity $u^{\prime}$ and integral length scale $L_{T}$ ) are the same for all three fuels. This assumption is based on the fact that the turbulent charge motion is fuel independent and it depends rather on the geometrical characteristics of the combustion chamber and of the intake duct [56]. The laminar burning speed, used for the determination of the combustion regime, is the unstretched laminar burning speed. Examples of its use can be found in $[23,57]$.

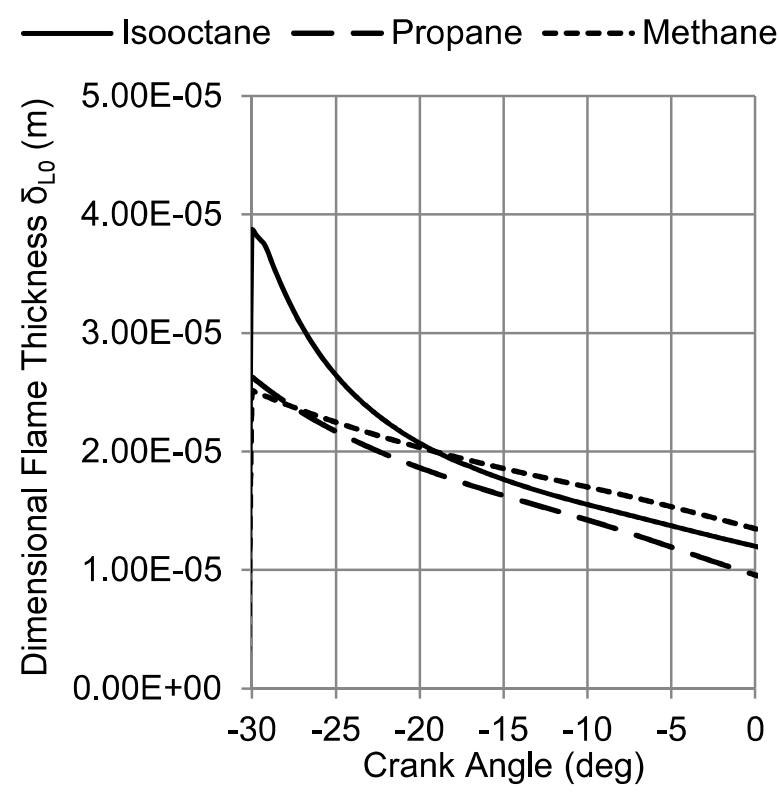

Figure 5: Dimensional (or diffusive) laminar flame thickness.

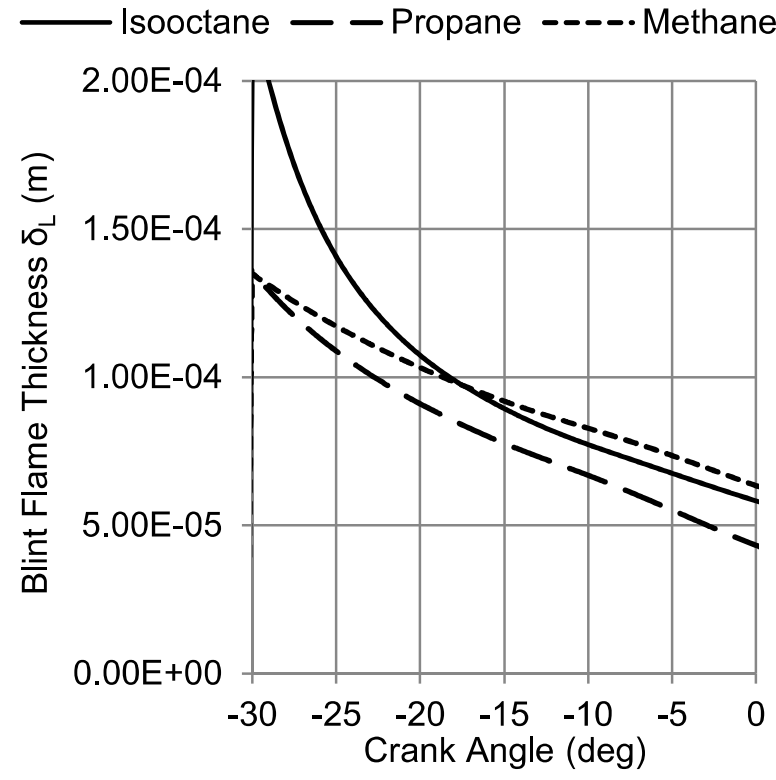

Figure 6: Laminar flame thickness calculated with Blint's correlation [42].

As already mentioned, the mixtures were intentionally selected so as to ensure an identical unstretched laminar burning speed for all three fuels. Therefore, the laminar flame thickness is the only laminar flame characteristic which changes among the three mixtures. The laminar flame 
thickness for all three fuels is shown in Figure 5 (equation (5)) and Figure 6 (equation (6)). The main conclusion that can be drawn from these figures is that propane and methane have almost the same laminar flame thickness. This is explained by the fact that the thermal diffusivities of the two fuels are extremely close, whereas the flame thickness of isooctane is $40 \%$ greater than that of the other two fuels. This difference will have an impact on the efficiency function and on flame wrinkling. However, the laminar flame thickness is sufficiently small for all the turbulent scales to wrinkle the flame front. Consequently, it is expected that the flame thickness difference of isooctane will have a minor effect on flame wrinkling.

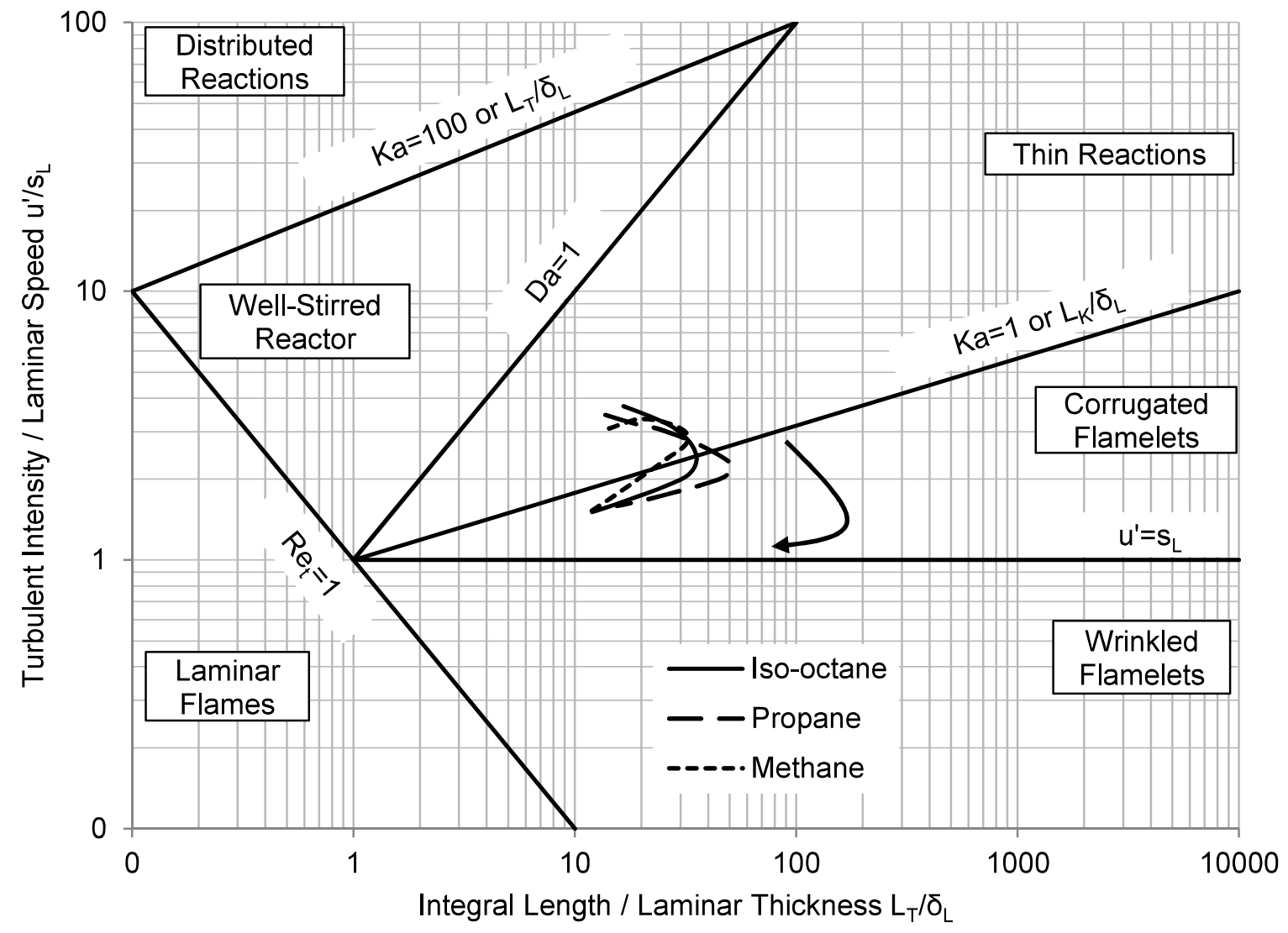

Figure 7: Borghi-Peters diagram showing the combustion regimes for all three fuels. The black arrow shows the direction of the combustion process. The unstretched laminar burning speed and Blint's [42] laminar flame thickness were used to calculate the combustion regime.

The Borghi-Peters diagram of premixed combustion can provide qualitative information about the flame during the simulation. In order to assess the phenomenology of the structure of premixed flames as determined by their interaction with the turbulent flow field, the flames were positioned 
on the regime diagram of premixed turbulent combustion modes (Figure 7). In this diagram, initially postulated by Borghi [57] and later extended by Peters [23], the various modes of premixed turbulent combustion are identified by comparing turbulence and chemical characteristic time scales. Through chemical and flow phenomena, the nature and characteristics of combustion are revealed. All three fuel mixtures are found in the same combustion regimes of 'thin reactions' (flames) and 'corrugated flames'. Propane and methane mixtures show an almost identical combustion regime and it can be expected that their wrinkling behavior will also be similar.

The efficiency function, used in this 0D model (equation in [50]), was calculated by the Meneveau and Poinsot equation [50] with an one-step chemistry of an Arrhenius law for the description of the combustion process (Lewis number of 1.2). Notwithstanding the effect of the constant Lewis number upon the calculation of the efficiency function, fuel dependence exists through the use of the laminar flame thickness. An updated version of the efficiency function was proposed by Bougrine et al. in [25]. It contains a 4-step kinetic scheme dedicated to the combustion of methanehydrogen and propane-hydrogen fuel blends. Subsequently, the same authors proposed a new efficiency function which contains a correction term as a function of the Lewis number. In the discussion of the results shown on Figure 4 (stretched and unstretched speed), it was shown that the Lewis number has a significant impact on the beginning of combustion. This impact of fuel composition on the early flame development is not taken into account by the updated efficiency function, since the efficiency function describes the turbulence-flame interaction of a fully turbulent flame rather than the flame after ignition (as explained in [58]). Hence, it is necessary to model the stretched laminar burning speed even if a turbulence-flame interaction model takes into account fuel composition effects through the Lewis number.

The flame radius evolution for all three fuels along with the experimental measurements (acquired from [21]) are plotted in Figure 8. The simulation curves are close to the experimental points and 
they have the same ranking: methane flame propagates more rapidly, followed by propane while isooctane has the slowest propagation. The same trend was observed in $[19,20]$. The simulation radii are always lower than the experimental ones. This divergence is probably due to the different way in which the flame front radius is calculated in the model and in the experiment. In the experimental study, the flame radius is deduced from tomographic images. This means that the flame radius is obtained from a surface and does not take into account the three-dimensional shape of the flame, unlike the model. The simulation radius is calculated so that the thermodynamic burnt gas volume $V_{b}$ is equal to the volume $V_{L}$, which is enclosed by the mean flame surface.

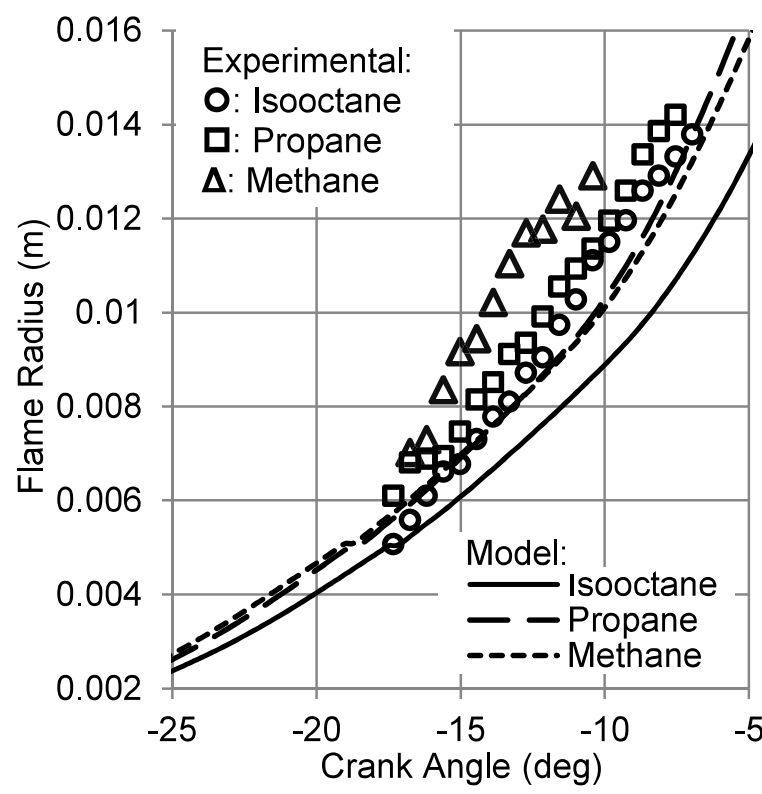

Figure 8: Flame Radius $\left(R_{f}\right)$ during the first stage of combustion for all three fuels along with the experimental values $(+)$ from $[21]$.

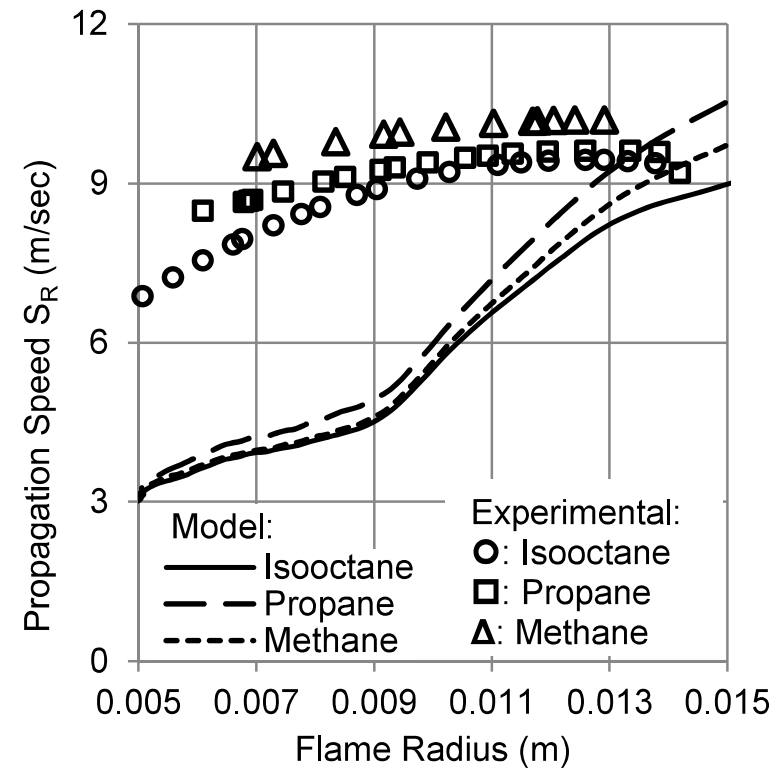

Figure 9: Equivalent propagation speed $\left(s_{R}\right)$ during the first stage of combustion for all three fuels along with the experimental values $(+)$ from $[21]$.

The flame propagation speed as defined by equation (3) is shown in Figure 9, as a function of flame radius. In accordance with the slow evolution of the isooctane radius already identified, the propagation speed of the isooctane mixture is the lowest in both modeling and experimental results. The methane flame propagates faster than the propane flame in the experiments, while they seem to have the same propagation speed in modeling results. An inflexion point on all three modeling curves appears between 0.009 and $0.010 \mathrm{~m}$ of flame radius. At this point the spherical flame 
surface touches the piston and continues to expand towards the cylinder wall. This inflexion point is not visible on experimental data, again due to the optical diagnostic used in [4]. As the tomographic image was taken with a laser sheet parallel to the piston plane, the moment when the flame reaches the piston is not visible. In spite of the fact that the simulated flame radii are close to experimental data (Figure 10), the simulated propagation speed results do not show the same behavior as the experimental values. This is due to the derivation of the simulated radius values (see equation (3)).

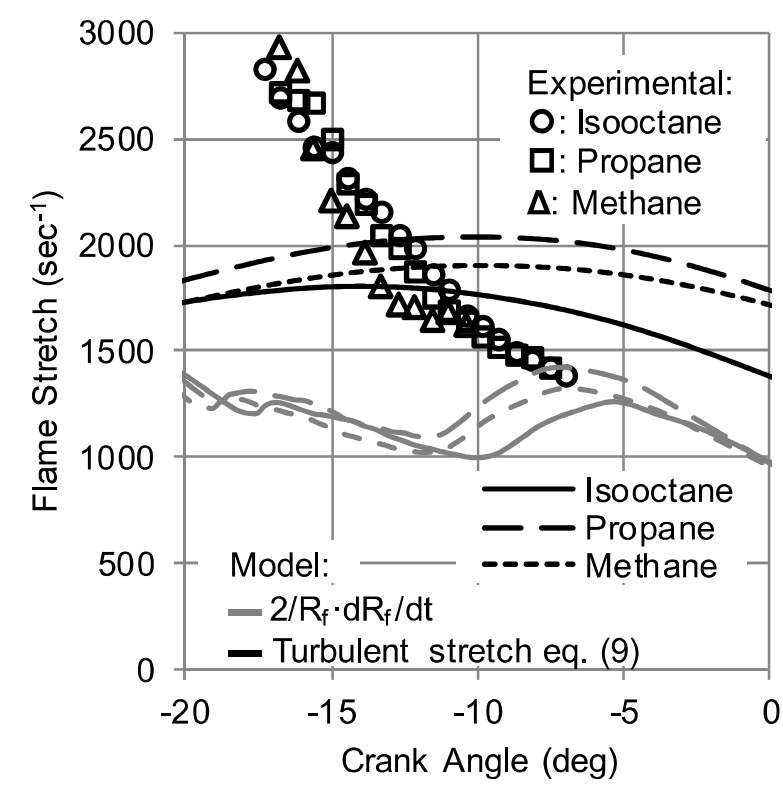

Figure 10: Turbulent flame stretch and curvature during the first stage of combustion for all three fuels along with the experimental values $(+)$ from [21].

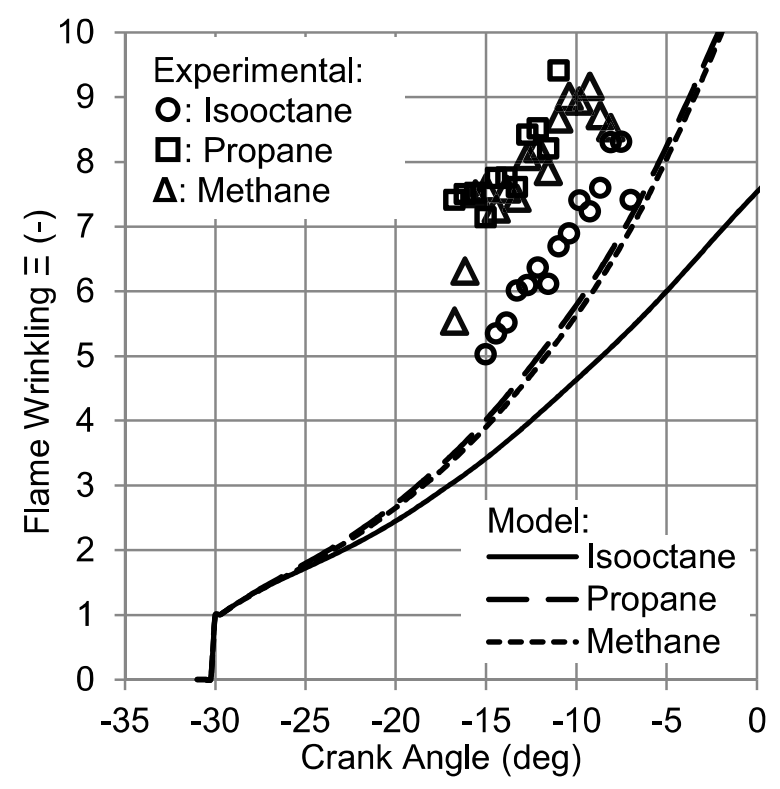

Figure 11: Simulated wrinkling factor $(\Xi)$ during the first stage of combustion for all three fuels along with the experimental values $(+)$ from $[21]$.

Turbulent flame stretch, calculated by equation (10) (first RHS term), as well as flame curvature multiplied by flame speed, which is the definition used for flame stretch in the experiments, are plotted for all three fuel mixtures in Figure 10. Numerical and experimental results are in the same order of magnitude and for both of them, the three fuels have almost the same stretch. Experimental results show a decrease of flame stretch during combustion, which is expected due to the diminishing curvature term (see equation (13)), as it is inversely proportional to the flame radius $\left(R_{f}\right)$. The modeling approach of flame stretch for both curvature and turbulent term gives values 
of the same order of magnitude as the experimental ones. It can be seen that the turbulent stretch obtained from the first RHS term of equation (10) is quite constant whereas the curvature contribution to stretch shows a decrease, as do the experimental values, from -20 to -10 CAD. After -10 CAD, the flame reaches the piston head and the flame curvature increases so that it cannot be investigated anymore. However, the decrease of the flame curvature term observed with the model appears to be in good agreement with the experimental results thus highlighting the fact that the decrease of the flame kernel stretch is mainly driven by the curvature. The importance of taking into account the flame curvature effect on the flame propagation is here shown.

From experiments, the flame wrinkling was also calculated by the use of flame radius: $\Xi=$ $\left(R_{p} / R_{S}\right)^{2}$, where $R_{p}$ is the radius deduced from the perimeter of the flame contour and $R_{S}$ the radius deduced from the burnt gas surface [19] as follows:

$$
\begin{gathered}
R_{p}=\frac{A_{\text {image }}}{2 \pi} \\
R_{s}=\sqrt{\frac{A_{\text {image }}}{\pi}}
\end{gathered}
$$

with $A_{\text {image }}$, the flame surface obtained from tomographic images in [21].

The global wrinkling of the three mixtures from modeling is shown along with the experimental results in Figure 11. Both numerical and experimental results exhibit an increase in flame wrinkling during the first part of combustion. In the model, the wrinkling factor starts at the spark advance timing with a value equal to one in order to simulate the laminar nature of the flame kernel [59] and during $10 \mathrm{CAD}$ the simulated wrinkling value is similar for all models. This is expected since the flame front starts to be affected by turbulence when the flame kernel becomes larger than the integral length scale ( $L_{T}=1.9 \mathrm{~mm}$ at spark advance in all computations) [14]. Both simulated and numerical results give similar wrinkling for propane and methane mixtures and a lower one 
for isooctane. As explained in [21] and observed in Figure 10, the most stretch-sensitive mixture, i.e. isooctane, has the least wrinkled flame front. The Lewis number, being equal to or larger than unity, ensures thermodiffusive stability for all three fuels. Moreover, hydrodynamic (DarrieusLandau) instabilities have a minor impact since the Lewis numbers are so high that the impact of the highly turbulent flow on flame wrinkling is preponderant. These considerations lead to the conclusion that the lower wrinkling for isooctane is due to local flow-flame interactions. These local interactions, which are different for each mixture, are not identified by the $0 \mathrm{D}$ wrinkling model used in this study. Nevertheless, they are globally taken into account and a correct flame wrinkling is calculated. At -10 CAD, the simulated wrinkling of all three fuel mixtures reaches 60 $67 \%$ of the experimental value. From the observation of experimental and simulation flame wrinkling results, it can be noted that the derivation of the wrinkling factor from tomographic images by the use of radii gives higher wrinkling than the simulated values, since it was not obtained using the same approach for experiments and simulation. Another possible explanation for the discrepancy between the simulated and experimentally derived wrinkling is the difference in flame stretch between experiment and simulation, as explained in the previous paragraph. In fact, the higher stretch for experimental results at the beginning of combustion leads to a lower stretched laminar burning speed compared to the numerical ones. By considering that the flame wrinkling can be defined as the ratio of the turbulent flame speed to the laminar flame, the lower flame speed for the experiments leads to a higher wrinkling for experiments than for simulation. Although the wrinkling modeling can be improved, the agreement between experiment and simulation shows that the calculation of a global wrinkling factor is relevant and that the use of the curvature dependence is needed for modeling purposes. However, instead of considering the unstretched laminar burning speed for wrinkling in equation (10), a stretched burning speed depending on the flame stretch should be considered as was done by Richard et al. [29]. Besides, 
since the flame is considered laminar in the early stage of combustion in the model, flame wrinkling is equal to one. Consequently, the flame stretch impact on consumption speed needs to be taken into account in the laminar flame speed formulation from the beginning of the simulation.
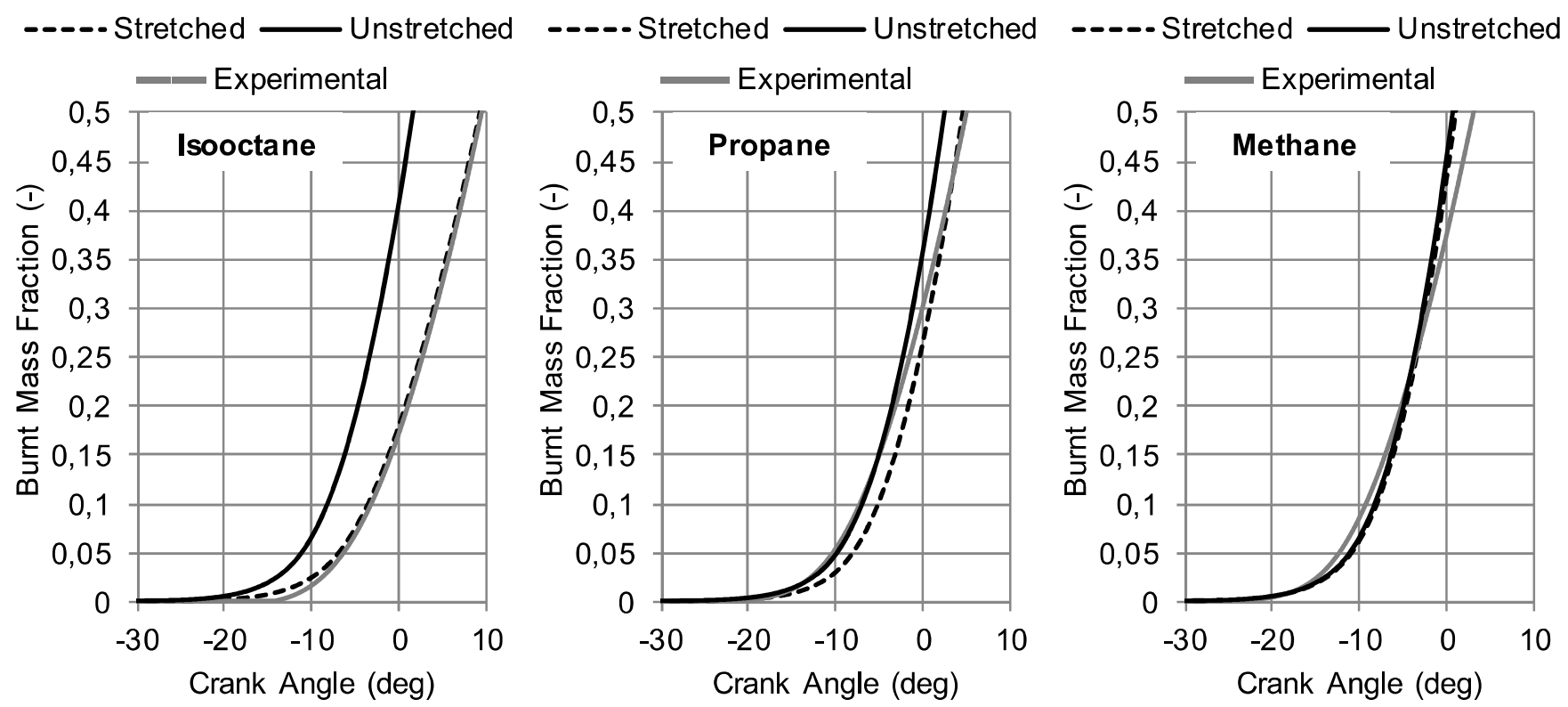

Figure 12: Simulated (with stretched and unstretched laminar burning speeds) burnt mass fractions compared with the experimental ones [21] for all three fuels: (a)Isooctane, (b)Propane, (c)Methane.

Figure 12 shows the burnt mass fraction (calculated by integrating equation (1)) up to 0.50 for all three mixtures. As already discussed in [21], mixtures do not burn with the same speed, with the isooctane mixture being the slowest and the methane mixture the fastest. With the help of the simulation results, the impact of stretch, through the Lewis number, on the laminar burning speed is visible. Indeed for lean hydrocarbon-air mixtures, since the Markstein number is positive, the effective laminar burning speed is lower than the unstretched laminar burning speed because of flame stretch. This leads to a slower flame propagation than the one predicted without taking flame stretch into account. The slower flame propagation due to flame stretch is then responsible for a slower increase in the burnt mass fraction. Consequently the trace of the burnt mass fraction is shifted to later in the engine cycle. For methane the two burnt mass fraction traces are almost identical, since the stretched and unstretched laminar burning speeds are similar. The Lewis 
number effect starts to be visible for propane (the unstretched trace is 2.5 degrees ahead of the stretched one at $50 \%$ ). The greatest impact is found for the isooctane mixture, where the unstretched trace is $7.5 \mathrm{CAD}$ ahead of the stretched trace at $50 \%$. When the stretched laminar burning speeds are used, the burnt mass fraction curves almost coincide with the experimental ones, thus validating the model.

Figure 13 displays the in-cylinder pressure traces at $1200 \mathrm{rpm}$ for all three fuels. As can be seen, the model shows good agreement with the experimental results. Besides, the importance of taking flame stretch into account is visible for propane and even more so for isooctane. For these fuels, the "Unstretched" curve displays a faster evolution and higher pressure values. This is due to the fact that the laminar flame speed is higher when not considering flame stretch and it is then responsible for a faster flame propagation and pressure increase. As previously said, for methane there is no difference with or without stretch since the fuel is not stretch sensitive.
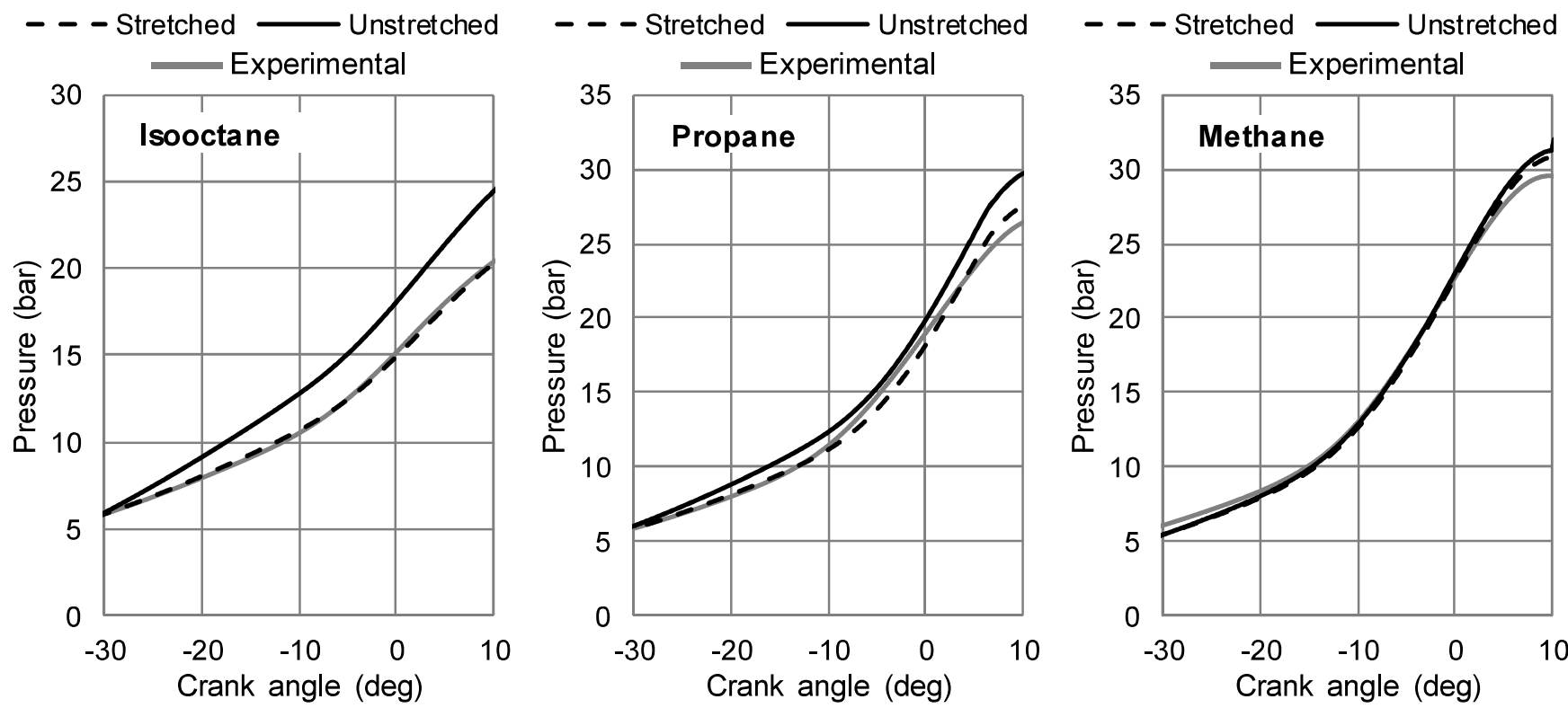

Figure 13: Simulated in-cylinder pressure traces at 1200 RPM compared with the experimental ones [21] for all three fuels: (a) Isooctane, (b) Propane, (c) Methane.

To ensure the model validation, another engine speed $(1600 \mathrm{rpm})$ was simulated using the stretched laminar burning speed model and compared to experimental results. Increasing the engine speed is responsible for a turbulent intensity increase [56] which leads to higher stretch levels in the early 
stages of flame propagation as shown in a previous study [19]. Figure 14 shows the burnt mass fraction at $1600 \mathrm{rpm}$ up to $50 \%$ for isooctane and methane which are the fuels having the greatest difference in terms of stretch sensitivity in this study. The model appears to be in excellent agreement with the experiments, thus validating the use of the model in taking account of the stretch effect.
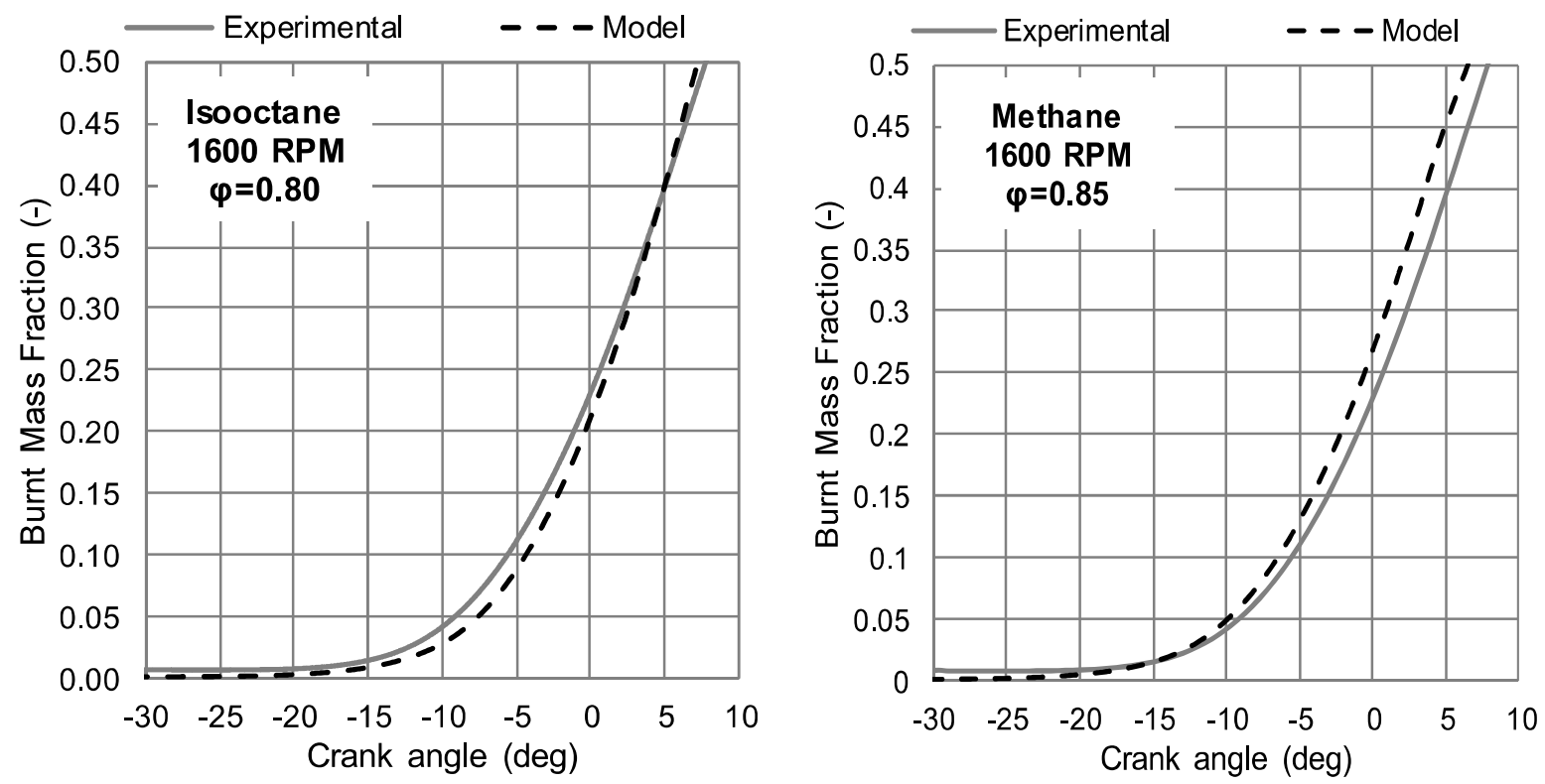

Figure 14: Simulated burnt mass fractions at $1600 \mathrm{rpm}$ compared to the experimental ones for (a) Isooctane, (b) Methane In-cylinder pressure traces at $1600 \mathrm{rpm}$ for isooctane and methane mixtures are also plotted in Figure 15. Results again show a very good agreement between experiments and simulation. 

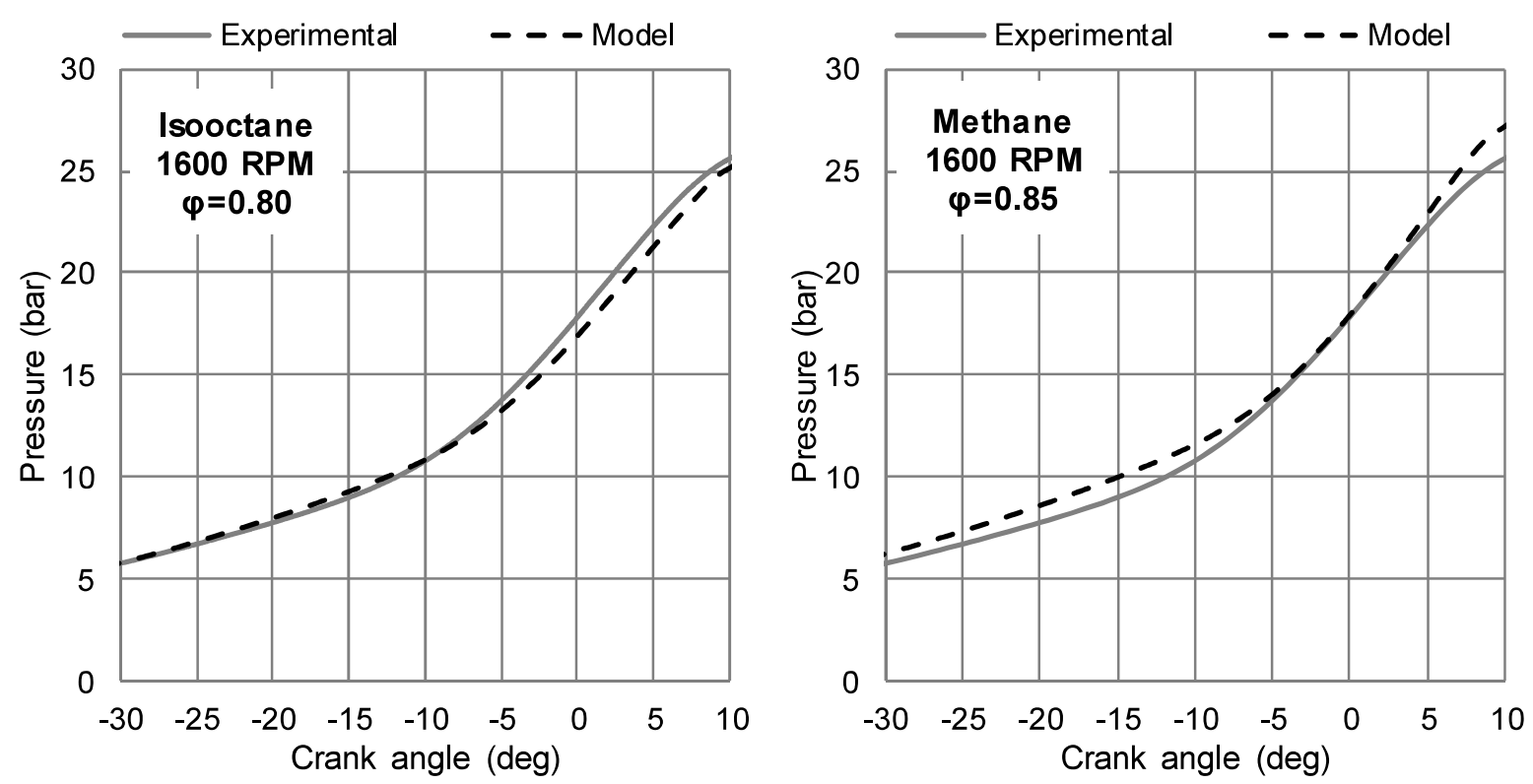

Figure 15: Simulated in-cylinder pressure traces at $1600 \mathrm{rpm}$ compared with experimental ones for (a) Isooctane and (b) Methane 


\section{Conclusion}

A 0D Spark Ignition combustion model was developed on the basis of the 0D Flame Surface Density equation, enhanced with a sub-model for laminar flame stretching. Simulation results were compared against previously published experimental results of different lean mixtures (isooctane, propane and methane) presenting almost the same unstretched laminar burning speed during the beginning of combustion.

The Lewis and Markstein numbers remain almost constant during the combustion cycle. Their values are in accordance with already published values for the same fuel/air equivalence ratio, pressure and temperature conditions. The correlation used for the unstretched laminar burning speed preserves the equality of the unstretched flame speeds of each mixture. The stretched speeds are ranked from low to high as follows: Isooctane (Le: 2.9), Propane (Le: 1.80) and Methane (Le: $0.99)$.

The model adopted for the stretched laminar burning speed is an indispensable addition in a physical combustion model because it adapts the laminar burning speed to the high stretch rate at the beginning of combustion, while during this stage flame wrinkling is low. The turbulent efficiency function takes the fuel composition partially into account through the laminar flame thickness but does not incorporate the effect of stretch even if it is corrected by the Lewis number. As a result, taking the effect of flame stretch into account is not only needed for the flame wrinkling equation as done by Richard et al. [29] but also for flame propagation especially during the early flame development where the flame stretch decrease is driven by the curvature.

Flame radius simulations show almost the same trends as the experimental results. The methane mixture propagates faster than propane in the experiments, while they seem to have the same propagation speed in modeling results. The differences in the simulated and experimental flame radius and propagation speeds are due to the different way in which flame radius is calculated: 
through two-dimensional tomographic images in the experiments, and by spherical surfaces in the model. The flame wrinkling trend is also reproduced by the model with propane and methane having almost identical wrinkling, while isooctane has lower values. The absolute values of the experiments are greater than those of simulations, due to the greater flame radii in experiments. Flame stretch is of the same order of magnitude for all three mixtures for simulations and experiments.

Finally, the impact of the stretched flame speed, through the Lewis number, is visible in the burnt mass fraction and in-cylinder pressure. The difference in combustion speed is not visible for methane, since its stretched speed is close to the unstretched one. Stretch impact becomes visible for propane, while it is dominant in the case of isooctane. As an increase in engine speed is responsible for higher stretch levels at the beginning of the kernel development, the model was also validated by comparing simulated in-cylinder pressure and burnt mass fraction traces to experimental ones at a higher engine speed. This conclusion underlines the need for flame stretch modeling for the first stage of combustion and offers insight for a future study on the various parameters which affect flame stretch, such as RBG fraction, engine speed, engine load and spark timing. If a more detailed flame stretch model becomes available, the impact of strain on the total flame stretch may also be reconsidered.

\section{References}

[1] Wang C, Xu H, Herreros JM, Wang J, Cracknell R. Impact of fuel and injection system on particle emissions from a GDI engine. Appl Energy 2014;132:178-91. doi:10.1016/j.apenergy.2014.06.012.

[2] Knop V, Michel J-B, Colin O. On the use of a tabulation approach to model auto-ignition during flame propagation in SI engines. Appl Energy 2011;88:4968-79. 
doi:10.1016/j.apenergy.2011.06.047.

[3] Sen AK, Zheng J, Huang Z. Dynamics of cycle-to-cycle variations in a natural gas directinjection spark-ignition engine. Appl Energy 2011;88:2324-34. doi:10.1016/j.apenergy.2011.01.009.

[4] Salvi BL, Subramanian KA. Experimental investigation and phenomenological model development of flame kernel growth rate in a gasoline fuelled spark ignition engine. Appl Energy 2015;139:93-103. doi:10.1016/j.apenergy.2014.11.012.

[5] Mariani A, Foucher F. Radio frequency spark plug: An ignition system for modern internal combustion engines. Appl Energy 2014;122:151-61. doi:10.1016/j.apenergy.2014.02.009.

[6] Vancoillie J, Demuynck J, Sileghem L, Van De Ginste M, Verhelst S, Brabant L, et al. The potential of methanol as a fuel for flex-fuel and dedicated spark-ignition engines. Appl Energy 2013;102:140-9. doi:10.1016/j.apenergy.2012.05.065.

[7] Wu X, Li Q, Fu J, Tang C, Huang Z, Daniel R, et al. Laminar burning characteristics of 2,5dimethylfuran and iso-octane blend at elevated temperatures and pressures. Fuel 2012;95:234-40.

[8] Wu X, Huang Z, Wang X, Jin C, Tang C, Wei L, et al. Laminar burning velocities and flame instabilities of 2,5-dimethylfurane-air mixtures at elevated pressures. Combust Flame 2011;158:539-46.

[9] Brequigny P, Dayma G, Halter F, Mounaïm-Rousselle C, Dubois T, Dagaut P. Laminar burning velocities of premixed nitromethane/air flames: An experimental and kinetic modeling study. Proc Combust Inst 2014;35:703-10. doi:10.1016/j.proci.2014.06.126.

[10] Pugh D, Crayford AP, Bowen PJ, O’Doherty T, Marsh R, Steer J. Laminar flame speed and 
markstein length characterisation of steelworks gas blends. Appl Energy 2014;136:102634. doi:10.1016/j.apenergy.2014.04.044.

[11] Boiarciuc A, Floch A. Evaluation of a 0D Phenomenological SI Combustion Model. SAE Tech Pap 2011. doi:10.4271/2011-01-1894.

[12] Candel SM, Poinsot TJ. Flame Stretch and the Balance Equation for the Flame Area. Combust Sci Technol 1990;70:1-15. doi:10.1080/00102209008951608.

[13] Halter F, Tahtouh T, Mounaïm-Rousselle C. Nonlinear effects of stretch on the flame front $\begin{array}{lll}\text { propagation. } & \text { Combust } & \text { Flame }\end{array}$ doi:10.1016/j.combustflame.2010.05.013.

[14] Renou B, Boukhalfa A. An Experimental Study of Freely Propagating Premixed Flames at Various Lewis Numbers. Combust Sci Technol 2001;162:347-70. doi:10.1080/00102200108952148.

[15] Chen Z. On the extraction of laminar flame speed and Markstein length from outwardly propagating spherical flames. Combust Flame n.d.;158:291-300. doi:10.1016/j.combustflame.2010.09.001.

[16] Bradley D, Hicks RA, Lawes M, Sheppard CGW, Woolley R. The Measurement of Laminar Burning Velocities and Markstein Numbers for Iso-octane-Air and Iso-octane-n-HeptaneAir Mixtures at Elevated Temperatures and Pressures in an Explosion Bomb. Combust Flame 1998;115:126-44. doi:10.1016/S0010-2180(97)00349-0.

[17] Bradley D, Lawes M, Mansour MS. Explosion bomb measurements of ethanol-air laminar gaseous flame characteristics at pressures up to $1.4 \mathrm{MPa}$. Combust Flame 2009;156:146270. doi:10.1016/j.combustflame.2009.02.007. 
[18] Kelley AP, Smallbone AJ, Zhu DL, Law CK. Laminar flame speeds of C5 to C8 n-alkanes at elevated pressures: Experimental determination, fuel similarity, and stretch sensitivity. Proc Combust Inst 2011;33:963-70. doi:10.1016/j.proci.2010.06.074.

[19] Brequigny P, Mounaïm-Rousselle C, Halter F, Moreau B, Dubois T. Impact of Fuel Properties and Flame Stretch on the Turbulent Flame Speed in Spark-Ignition Engines. SAE Tech Pap 2013. doi:10.4271/2013-24-0054.

[20] Aleiferis PG, Serras-Pereira J, Richardson D. Characterisation of flame development with ethanol, butanol, iso-octane, gasoline and methane in a direct-injection spark-ignition engine. Fuel 2013;109:256-78. doi:10.1016/j.fuel.2012.12.088.

[21] Brequigny P, Halter F, Mounaïm-Rousselle C, Moreau B, Dubois T. Thermodiffusive Effect on the Flame Development in Lean Burn Spark Ignition Engine. SAE Tech Pap 2014. doi:10.4271/2014-01-2630.

[22] Brequigny P, Halter F, Mounaïm-Rousselle C, Dubois T. Fuel performances in SparkIgnition (SI) engines: Impact of flame stretch. Combust Flame 2016;166:98-112. doi:10.1016/j.combustflame.2016.01.005.

[23] Peters N. The turbulent burning velocity for large-scale and small-scale turbulence. J Fluid Mech 1999;384:107-32. doi:http://dx.doi.org/10.1017/S0022112098004212.

[24] Dahms RN, Drake MC, Fansler TD, Kuo T-W, Peters N. Understanding ignition processes in spray-guided gasoline engines using high-speed imaging and the extended spark-ignition model SparkCIMM Part B: Importance of molecular fuel properties in early flame front propagation. Combust Flame 2011;158:2245-60. doi:10.1016/j.combustflame.2011.04.003. 
[25] Bougrine S, Richard S, Colin O, Veynante D. Fuel Composition Effects on Flame Stretch in Turbulent Premixed Combustion: Numerical Analysis of Flame-Vortex Interaction and Formulation of a New Efficiency Function. Flow, Turbul Combust 2014:1-23. doi:10.1007/s10494-014-9546-4.

[26] Bougrine S, Richard S, Michel J-B, Veynante D. Simulation of CO and NO emissions in a SI engine using a 0D coherent flame model coupled with a tabulated chemistry approach. Appl Energy 2014;113:1199-215. doi:10.1016/j.apenergy.2013.08.038.

[27] Payri F, Olmeda P, Martín J, García A. A complete 0D thermodynamic predictive model for direct injection diesel engines. Appl Energy 2011;88:4632-41. doi:10.1016/j.apenergy.2011.06.005.

[28] Demesoukas S, Caillol C, Higelin P, Boiarciuc A. Zero-Dimensional Spark Ignition Combustion Modeling - A Comparison of Different Approaches. SAE Tech. Pap., 2013. doi:10.4271/2013-24-0022.

[29] Richard S, Veynante D. A 0-D flame wrinkling equation to describe the turbulent flame surface evolution in SI engines. Comptes Rendus Mécanique 2015;343:219-31. doi:10.1016/j.crme.2014.09.003.

[30] Demesoukas S, Caillol C, Higelin P, Boiarciuc A, Floch A. Near wall combustion modeling in spark ignition engines. Part A: Flame-wall interaction. Energy Convers Manag 2015;106:1426-38. doi:10.1016/j.enconman.2015.09.061.

[31] Demesoukas S, Caillol C, Higelin P, Boiarciuc A, Floch A. Near wall combustion modeling in spark ignition engines. Part B: Post-flame reactions. Energy Convers Manag 2015;106:1439-49. doi:10.1016/j.enconman.2015.10.022. 
[32] Woschni G. A universally applicable equation for the instantaneous heat transfer coefficient in the internal combustion engine. SAE Tech Pap 1967.

[33] Ferguson CR, Kirkpatrick AT. Internal Combustion Engines: Applied Thermosciences. 2000.

[34] Demesoukas S. 0D/1D combustion modeling for the combustion systems orptimization of spark ignition engines. Université d'Orléans, France, 2015.

[35] Fanelli E, Viggiano A, Braccio G, Magi V. On laminar flame speed correlations for H2/CO combustion in premixed spark ignition engines. Appl Energy 2014;130:166-80. doi:10.1016/j.apenergy.2014.05.012.

[36] Galloni E, Fontana G, Palmaccio R. Effects of exhaust gas recycle in a downsized gasoline engine. Appl Energy 2013;105:99-107. doi:10.1016/j.apenergy.2012.12.046.

[37] Wei H, Zhu T, Shu G, Tan L, Wang Y. Gasoline engine exhaust gas recirculation - A review. Appl Energy 2012;99:534-44. doi:10.1016/j.apenergy.2012.05.011.

[38] Galmiche B, Halter F, Foucher F. Effects of high pressure, high temperature and dilution on laminar burning velocities and Markstein lengths of iso-octane/air mixtures. Combust Flame 2012;159:3286-99. doi:10.1016/j.combustflame.2012.06.008.

[39] Razus D, Oancea D, Brinzea V, Mitu M, Movileanu C. Experimental and computed burning velocities of propane-air mixtures. Energy Convers Manag 2010;51:2979-84. doi:10.1016/j.enconman.2010.06.041.

[40] Liao SY, Jiang DM, Cheng Q. Determination of laminar burning velocities for natural gas. Fuel 2004;83:1247-50. doi:10.1016/j.fuel.2003.12.001.

[41] Poinsot T, Veynante D. Theoretical and Numerical Combustion 3rd Edition. 2012. 
[42] Blint RJ. The Relationship of the Laminar Flame Width to Flame Speed. Combust Sci Technol 1986;49:79-92. doi:10.1080/00102208608923903.

[43] Bird R, Stewart W, Lightfoot E. Transport phenomena. John Wiley \& Sons; 2007.

[44] Kee RJ, Dixon-Lewis G, Warnatz J, Coltrin ME, Miller JA. A FORTRAN computer code package for the evaluation of gas-phase multicomponent transport properties. Sandia Rep 1986;SAND86-824:3-39.

[45] Bozza F, Gimelli A, Strazzullo L, Torella E, Cascone C. Steady-State and Transient Operation Simulation of a "Downsized" Turbocharged SI Engine. SAE Tech Pap 2007;2007:776-90. doi:10.4271/2007-01-0381.

[46] Pajot O, Mounaïm-Rousselle C, Queiros-Conde D. New Data on Flame Behaviour in Lean Burn S.I. Engine. SAE Tech Pap 2001. doi:10.4271/2001-01-1956.

[47] Bozza F, Gimelli A, Federico N, Merola SS, Vaglieco BM. Validation of a Fractal Combustion Model through Flame Imaging. SAE Tech Pap 2005. doi:10.4271/2005-011120.

[48] Bozza F, Fontana G, Galloni E, Torella E. 3D-1D Analyses of the Turbulent Flow Field, Burning Speed and Knock Occurrence in a Turbocharged SI Engine. 8th Int. Conf. Engines Automob., 2007. doi:10.4271/2007-24-0029.

[49] Richard S, Bougrine S, Font G, Lafossas FA, le Berr F. On the Reduction of a 3D CFD Combustion Model to Build a Physical 0D Model for Simulating Heat Release, Knock and Pollutants in SI Engines. Oil Gas Sci Technol 2009;64:223-42. doi:10.2516/ogst/2008055.

[50] Meneveau C, Poinsot T. Stretching and quenching of flamelets in premixed turbulent combustion. Combust Flame 1991;86:311-32. doi:10.1016/0010-2180(91)90126-V. 
[51] Duclos J, Veynante D, Poinsot T. A comparison of flamelet models for premixed turbulent combustion. Combust Flame 1993;95:101-17. doi:10.1016/0010-2180(93)90055-8.

[52] Bechtold JK, Matalon M. The dependence of the Markstein length on stoichiometry. Combust Flame 2001;127:1906-13.

[53] Müller UC, Bollig M, Peters N. Approximations for burning velocities and markstein numbers for lean hydrocarbon and methanol flames. Combust Flame 1997;108:349-56. doi:http://dx.doi.org/10.1016/S0010-2180(96)00110-1.

[54] Dahms RN, Drake MC, Fansler TD, Kuo T-WW, Peters N. Understanding ignition processes in spray-guided gasoline engines using high-speed imaging and the extended spark-ignition model SparkCIMM. Part A: Spark channel processes and the turbulent flame front propagation. Combust Flame 2011;158:2245-60. doi:10.1016/j.combustflame.2011.03.012.

[55] Foucher F, Mounaïm-Rousselle C. Fractal approach to the evaluation of burning rates in the vicinity of the piston in a spark-ignition engine. Combust Flame 2005;143:323-32. doi:10.1016/j.combustflame.2005.06.007.

[56] Heywood JB. Internal combustion engine fundamentals. McGraw-Hill; 1988.

[57] Borghi R. On the structure and morphology of turbulent premixed flames. Recent Adv Aerosp Sci 1985.

[58] Richard S, Colin O, Vermorel O, Benkenida A, Angelberger C, Veynante D. Towards large eddy simulation of combustion in spark ignition engines. Proc Combust Inst 2007;31:3059_ 66. doi:10.1016/j.proci.2006.07.086.

[59] Herweg R, Maly RR. A Fundamental Model for Flame Kernel Formation in S. I. Engines. 
SAE Tech Pap 1992. doi:10.4271/922243. 